\title{
Prolyl-hydroxylase inhibition induces SDF-1 associated with increased CXCR4+/CD11b+ subpopulations and cardiac repair
}

\author{
Santhosh Kumar Ghadge ${ }^{1} \cdot$ Moritz Messner $^{1} \cdot$ Thi Van Pham ${ }^{2}$. \\ Maximilian Doppelhammer ${ }^{2}$ - Andreas Petry ${ }^{3}$ - Agnes Görlach ${ }^{3}$ • Britta Husse ${ }^{1}$. \\ Wolfgang-Michael Franz ${ }^{1} \cdot$ Marc-Michael Zaruba $^{1}$
}

Received: 19 October 2016 /Revised: 27 April 2017 / Accepted: 4 May 2017 / Published online: 26 May 2017

(C) The Author(s) 2017. This article is an open access publication

\begin{abstract}
SDF-1/CXCR4 activation facilitates myocardial repair. Therefore, we aimed to activate the HIF- $1 \alpha$ target genes SDF- 1 and CXCR4 by dimethyloxalylglycine (DMOG)-induced prolyl-hydroxylase $(\mathrm{PH})$ inhibition to augment CXCR4+ cell recruitment and myocardial repair. SDF-1 and CXCR4 expression was analyzed under normoxia and ischemia \pm DMOG utilizing SDF-1-EGFP and CXCR4-EGFP reporter mice. In bone marrow and heart, CXCR4-EGFP was predominantly expressed in CD45+/ $\mathrm{CD} 11 \mathrm{~b}+$ leukocytes which significantly increased after myocardial ischemia. PH inhibition with $500 \mu \mathrm{M}$ DMOG induced upregulation of SDF-1 mRNA in human microvascular endothelial cells (HMEC-1) and aortic vascular smooth muscle cells (HAVSMC). CXCR4 was highly elevated in HMEC-1 but almost no detectable in HAVSMC. In vivo, systemic administration of the PH inhibitor DMOG without pretreatment upregulated nuclear HIF- $1 \alpha$ and SDF-1 in the ischemic mouse heart associated with increased recruitment of CD45+/CXCR4-EGFP+/CD11b+
\end{abstract}

Santhosh Kumar Ghadge and Moritz Messner contributed equally to this work.

Electronic supplementary material The online version of this article (doi:10.1007/s00109-017-1543-3) contains supplementary material, which is available to authorized users.

Marc-Michael Zaruba

Marc-Michael.Zaruba@i-med.ac.at

1 Department of Internal Medicine III, Cardiology and Angiology, Medical University Innsbruck, Innsbruck, Austria

2 Klinikum Grosshadern, Medical Department I, Ludwig Maximilians University, Munich, Germany

3 Department of Pediatric Cardiology and Congenital Heart Disease, Experimental Pediatric Cardiology. German Heart Center Munich, TU Munich, Munich, Germany cell subsets. Enhanced PH inhibition significantly upregulated reparative M2 like CXCR4-EGFP+CD11b+/CD206+ cells compared to inflammatory M2-like CXCR4-EGFP+ CD11b+/ CD86+ cells associated with reduced apoptotic cell death, increased neovascularization, reduced scar size, and an improved heart function after MI. In summary, our data suggest increased $\mathrm{PH}$ inhibition as a promising tool for a customized upregulation of SDF-1 and CXCR4 expression to attract CXCR4+/CD11b+ cells to the ischemic heart associated with increased cardiac repair.

\section{Key messages}

- DMOG-induced prolyl-hydroxylase inhibition upregulates SDF-1 and CXCR4 in human endothelial cells.

- Systemic application of DMOG upregulates nuclear HIF$1 \alpha$ and SDF-1 in vivo.

- Enhanced prolyl-hydroxylase inhibition increases mainly CXCR4+/CD11b+ cells.

- DMOG increased reparative M2-like CD11b+/CD206+ cells compared to M1-like cells after MI.

- Enhanced prolyl-hydroxylase inhibition improved cardiac repair and heart function.

Keywords SDF-1 $\cdot$ CXCR4 $\cdot$ CD11b · Prolyl-hydroxylases inhibitors $\cdot$ Myocardial ischemia $\cdot \mathrm{HIF}-1 \alpha$

\section{Introduction}

Ischemic cardiomyopathy due to acute myocardial infarction (MI) or coronary artery disease is a major contributor for mortality and morbidity in the Western world with rising incidence $[1,2]$. Although pharmacological therapies can limit progression to chronic end-stage heart failure, repair of functional myocardium is very limited. Stromal cell-derived factor-1 
(SDF-1) and its corresponding receptor CXCR4 have been shown to play prominent roles during cardiovascular development, cardiac repair, and tissue homeostasis after ischemia [3]. We could demonstrate that a dual therapy consisting of (stem) cell mobilization with granulocyte-colony stimulating factor (G-CSF) and stabilization of SDF-1 by preventing its cleavage through inhibition of the protease CD26 increased recruitment of blood-derived progenitor cells associated with attenuated post-MI remodeling, improved myocardial function, and increased survival in mice [4]. Combined G-CSF treatment with dipeptidyl peptidase-IV (DPP-IV) inhibition limiting the proteolytic degradation of SDF-1 plus cell cycle activation in cardiomyocytes even enhanced cardiac regeneration after MI [5]. SDF-1 is upregulated for only ca. 3 days after MI, limiting the targeting of circulating CXCR4+ progenitors to ischemic myocardium over a longer period of post-infarct remodeling [6]. Consequently, various groups have developed strategies to overexpress SDF-1 mRNA or deliver SDF-1 protein after acute myocardial infarction in the heart to attenuate ischemic cardiomyopathy [7-9]. As a hindrance, these strategies rely on invasive procedures with the risk for infections and bleeding. From a translational aspect, it would be desirable to customize SDF-1 and CXCR4 gene expression pharmacologically in a time-dependent manner. Hypoxia-inducible factor (HIF) prolyl-hydroxylases seem to be attractive tools to achieve this goal: SDF-1 and CXCR4 gene expression is regulated by HIF- $1 \alpha$, which can bind to both promoters $[10,11]$. Since HIF- $1 \alpha$ degradation is triggered by oxygen-sensitive hydroxylation of two conserved proline residues by HIF-prolyl-hydroxylases, inhibition of the latter may enforce SDF-1 and CXCR4 gene expression and stimulate cardiac repair in the ischemic heart. In line with that assumption, a recently published study suggests that early activation of CXCR4 in cardiomyocytes after a single intramyocardial injection of the HIF-prolyl-hydroxylase inhibitor DMOG improved myocardial function by preventing cardiomyocyte cell death [12]. However, this study neither analyzed HIF- $1 \alpha$ activation and SDF-1 expression nor investigated recruitment of CXCR4+ cells from the bone marrow (BM) and heart. Therefore, we hypothesized that DMOG-induced PH inhibition may activate SDF-1 expression to augment CXCR4+ cell recruitment for cardiac repair.

\section{Methods (an expanded methods section is available in the online supplement)}

\section{Surgical induction of myocardial infarction in mice}

Myocardial infarction was induced in 10-12-week-old CXCR4-EGFP and C57BL/6 mice by surgical occlusion of the left anterior descending artery (LAD) through a left anterolateral approach as described previously [4]. Animal care and all experimental procedures are performed in strict accordance to the Austrian and National Institutes of Health animal legislation guidelines.

\section{Fluorescent-activated cell sorting (FACS) of BM and heart cells}

Ten- to 12-week-old CXCR4-EGFP BAC transgenic reporter mice with or without LAD ligation were either treated with saline or DMOG $(80 \mathrm{mg} / \mathrm{kg} /$ day) for up to 7 days. BM mononuclear and myocyte-depleted cardiac cells were separated as previously described [4]. Cells were incubated for $40 \mathrm{~min}$ in the dark at $4{ }^{\circ} \mathrm{C}$ with the following fluoresceinisothiocyanate (FITC)-, phycoerythrin (PE)-, and peridininchlorophyllprotein (PerCP)-conjugated monoclonal antibodies: CD45PerCP, CD11b-PerCP, CD11b-PE, CD4-PE, CD20-PE, CD31-PE, CD34-PE, Flk-PE, CD86-PE, CD206-PE, F4/80PE, CD133-PE, c-kit-PE, Sca-1-PE, CD3-biotin, CD45R/ B220-biotin, CD11b-biotin, TER-119-biotin, and Ly-6Gbiotin (all from BD Pharmingen). Matching isotype antibodies (BD Pharmingen) served as controls. Cells were analyzed by three-color flow cytometer using a Coulter Epics XLMCLTM flow cytometer (Beckman Coulter). Each analysis included 50,000 events.

\section{Expression analyses of SDF-1 and CXCR4 mRNA in human HMEC-1, HAVSMC, and murine BM cells}

Human microvascular endothelial cells (HMEC-1; CDC, Atlanta, GA) and human aortic vascular smooth muscle cells T/G HAVSMC (HAVSMC; American Type Culture Collection, Manassas, VA) were grown according to the manufacturer. For expression analyses in BM cells, DMOGtreated and control $(\mathrm{C} 57 \mathrm{BL} / 6 \mathrm{~J})$ mice were sacrificed and mononuclear BM cells were collected by Ficoll density gradient centrifugation. Total RNA was reverse-transcribed using the QuantiTect RT kit (Qiagen) according to manufacturer's protocol. Exon spanning primers for human and mouse SDF1, CXCR4, GAPDH, and $\beta$-actin were designed (Supplementary Table 1). Using $2 \times$ SYBR green mastermix (Applied Biosystems, USA), quantitative gene expression was calculated using the comparative $\Delta \Delta \mathrm{Ct}-$ method (for detailed protocol, see online supplement).

\section{Western blot}

For HIF- $1 \alpha$ studies cytosolic and nuclear fractions were isolated as described previously [13]. SDS-PAGE and blotting analysis were done using the following antibodies: HIF-1 $\alpha$ (rabbit polyclonal against HIF-1 $\alpha$, ab82832 Abcam), TATA binding protein (TBP) (mouse monoclonal against TBP, ab51841, Abcam), and GAPDH (mouse monoclonal to GAPDH, ab8245, Abcam). Appropriate horseradish- 

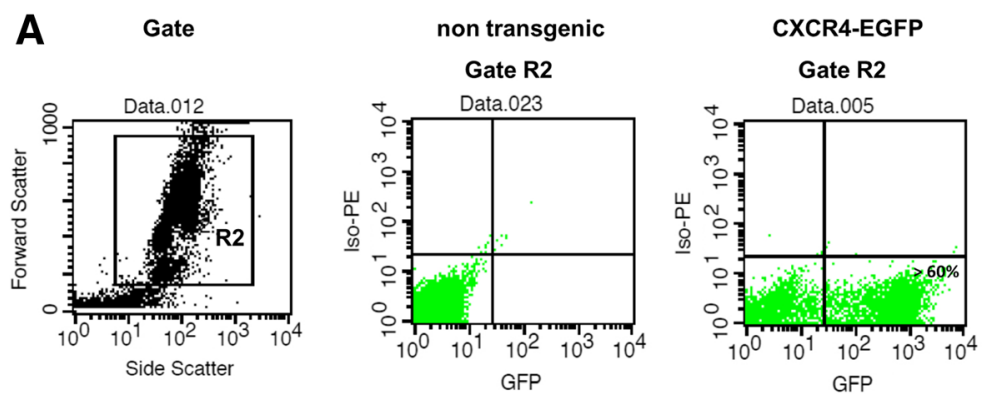

CXCR4-EGFP/CD45+/CD11b+

$\%$ CXCR4+/CD11b+ cells
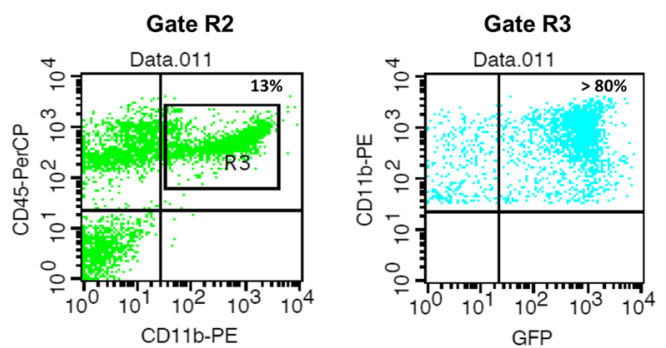

B

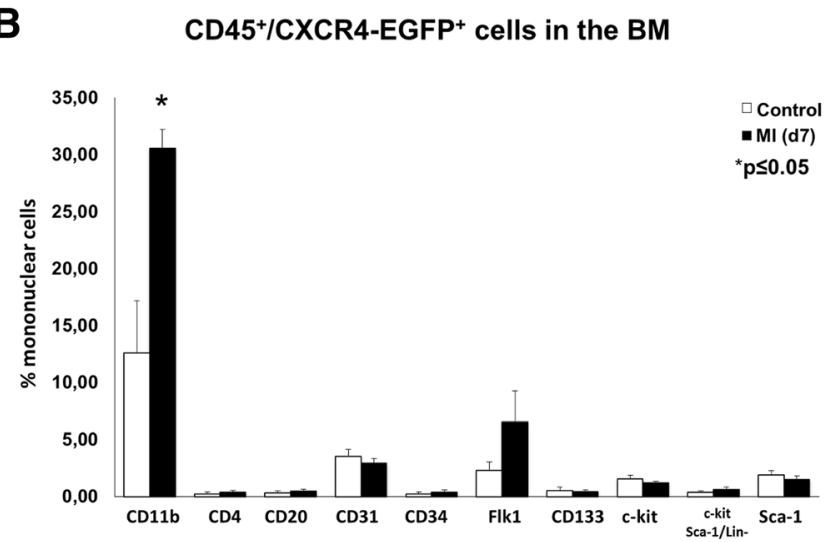

Fig. 1 FACS analysis of CXCR4-EGFP reporter mice display enhanced numbers of $\mathrm{CD} 45+/ \mathrm{CXCR} 4+/ \mathrm{CD} 11 \mathrm{~b}+$ cells in the BM and ischemic heart. a Representative FACS analysis of mononuclear BM cells from CXCR4-EGFP and non-transgenic littermate controls showing high

peroxidase-coupled secondary antibodies were used, and chemiluminescence was performed with ECL-Prime (Amersham). Western blot replicates were scanned and quantified using ImageJ computer-assisted densitometric analysis. HIF-1 $\alpha$ protein expression was normalized to GAPDH (cytosol) and TBP (nuclear compartment).

\section{Gene expression of HIF-1 target genes in the heart}

Heart tissues were minced and homogenized in TRIzol reagent (Invitrogen, USA), and total RNA was isolated according to the manufacturer's instructions. RNA was reverse-transcribed to cDNA using the QuantiTect RT kit (Qiagen). Exon spanning primers for the mouse HIF- $1 \alpha$ target genes vascular endothelial growth factor A (VEGF-A), pyruvate dehydrogenase kinase 1 (PDK1), and lactate dehydrogenase A (LDHA) were designed and are listed in Supplementary Table 1. Using $2 \times$ SYBR green mastermix (Applied Biosystems, USA), quantitative gene expressions were calculated using the comparative $\Delta \Delta \mathrm{Ct}-$ method with $\beta$-actin as a reference gene.

\section{SDF-1 ELISA}

A commercially available ELISA kit (R\&D systems, Mouse CXCL12/SDF-1 alpha Quantikine ELISA Kit) was used to

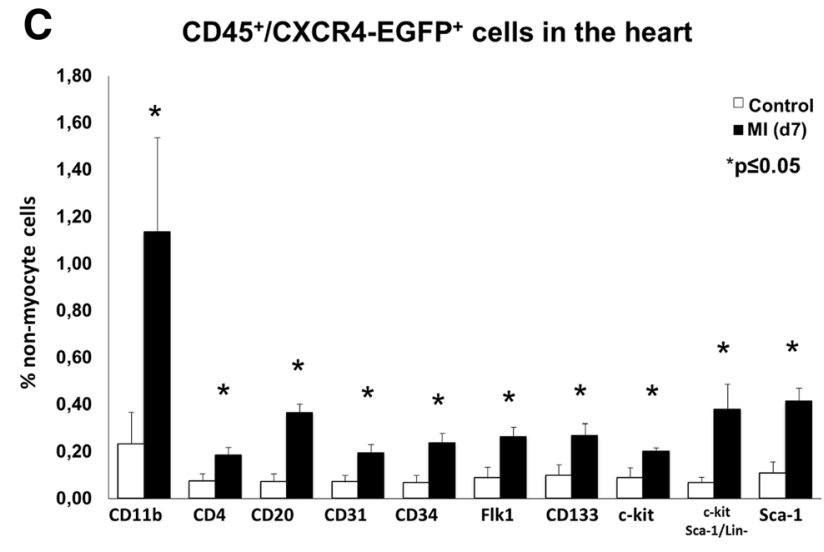

expression of CXCR4-EGFP+ on CD45+/CD11b+ cells. b, $\mathbf{c}$ Bar graph showing numbers of CD45+/CXCR4-EGFP+ cells in the BM and heart at day $7 \pm$ MI. All data represent mean $\pm \mathrm{SD}(n=4) ; * p<0.05$ control vs. MI

measure SDF-1 protein levels in heart lysates 7 days after myocardial infarction following manufacturer's instructions.

\section{Histology, immunostaining, and quantification of apoptosis and neovascularization}

Thirty days after MI, hearts $(n=10)$ were excised and fixed in $4 \%$ phosphate-buffered formalin and processed for analyses of scar size, wall thickness, capillary density, and TUNEL assay for apoptotic cells according to standard procedures (for detailed protocol, see online supplement) [14, 15]. Cardiomyocyte size was determined measuring myocyte cross-sectional area and minimum Feret's diameter from Masson's trichrome stained transverse sections at the periinfarct zone. Fifty cardiomyocytes per field were analyzed using ImageJ analysis software.

\section{Functional parameters}

To evaluate functional parameters, mice were randomly assigned to the following groups: sham-operated control mice $(n=5)$, saline-treated infarcted mice $(n=10)$, and DMOG $(80 \mathrm{mg} / \mathrm{kg}$ i.p. $)$-treated infarcted mice $(n=10)$. Pharmacological treatment was administered for up to 7 days post-MI (Supp. Fig. 1). Pressure-volume relations in vivo were analyzed 30 days after MI as previously described [4]. 


\section{HMEC-1 cells}

A

SDF-1

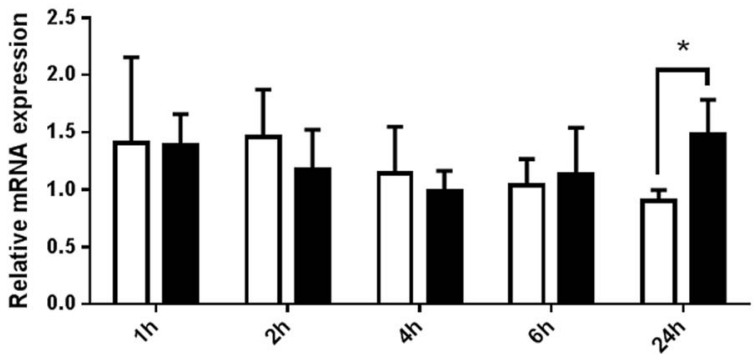

B CXCR4

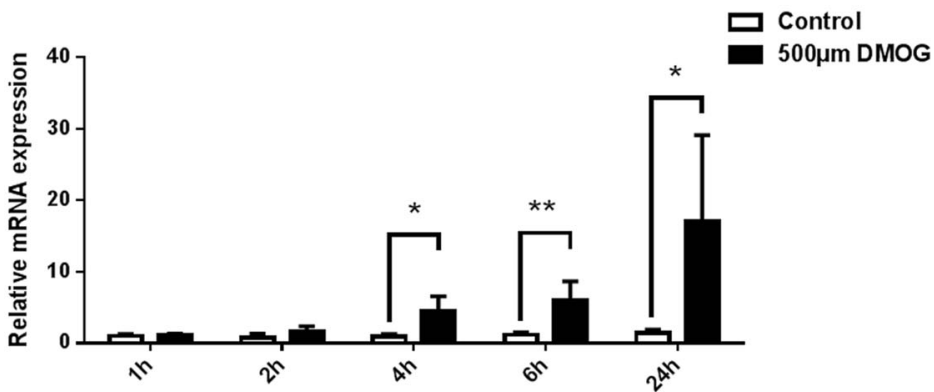

\section{Bone marrow (BM)}

C

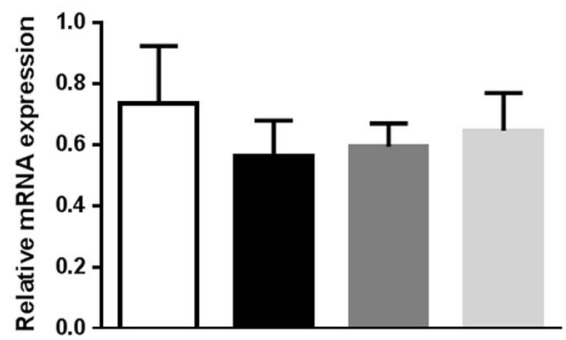

Fig. 2 DMOG increases SDF-1 and CXCR4 mRNA expression in a time- and dose-dependent manner in vitro and in vivo. a, b Expression of SDF-1 and CXCR4 mRNA in human endothelial HMEC-1 cells in vitro treated with $500 \mu \mathrm{M}$ of DMOG for 1, 2, 4, 6, and $24 \mathrm{~h}$. Data
D CXCR4

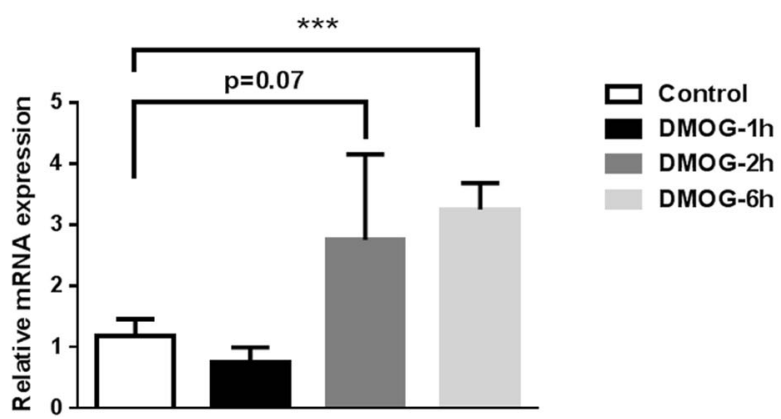

represent mean $\pm \mathrm{SD}(n=6) ; * p<0.05, * * p<0.01$ control vs. DMOG. c, d Expression of SDF-1 and CXCR4 mRNA in murine mononuclear BM cells in vivo treated with $80 \mathrm{mg} / \mathrm{kg}$ of DMOG i.p. for 1, 2, and $6 \mathrm{~h}$. Data represent mean $\pm \mathrm{SD}(n=4) ; * * * p 0.001$ control vs. DMOG

normoxia and ischemia. These mice contain multiple copies of a modified BAC in which the enhanced green fluorescent protein (EGFP) reporter gene was inserted immediately upstream of the coding sequence of CXCR4 [16]. Figure 1a shows representative FACS analyses of mononuclear BM cells from non-transgenic controls and CXCR4-EGFP reporter mice gated for leukocytes (gate R2). Roughly $>60 \%$ of the gated BM cells stained positive for CXCR4-EGFP. Gating of CD45PerCP and CD11b-PE-positive cells revealed that $>80 \%$ of $\mathrm{CD} 11 \mathrm{~b}+$ cells co-expressed CXCR4-EGFP. For further analyses, a broad panel of different leukocyte cell markers was used to screen for subsets of CXCR4-EGFP+ expressing cells. As shown in Fig. 1b, CD45+/CXCR4-EGFP+ was most frequently expressed in monocytic CD11b+ BM cells. Seven days after ischemia, particularly CD45+/CXCR4-EGFP+/CD11b+ cells significantly increased, whereas CD45-/CXCR4-EGFP+ cells were only rarely detected in BM and did not significantly change after MI (Supp. Fig. 2A). In the 
A

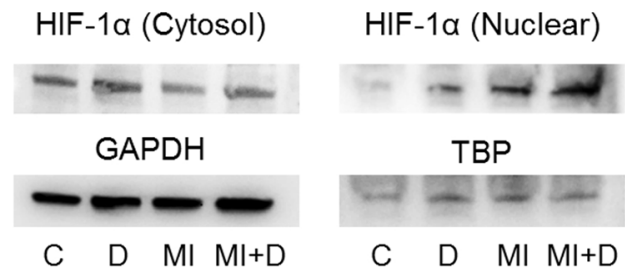

B

HIF-1 $\alpha$

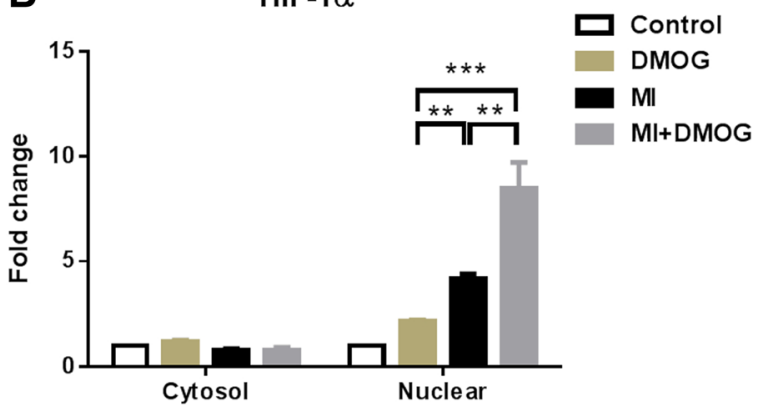

C

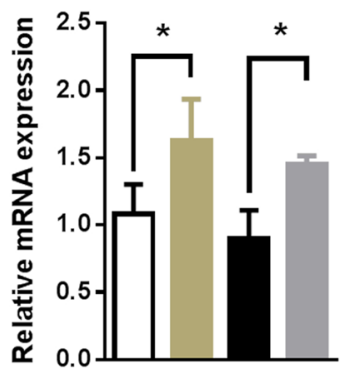

D

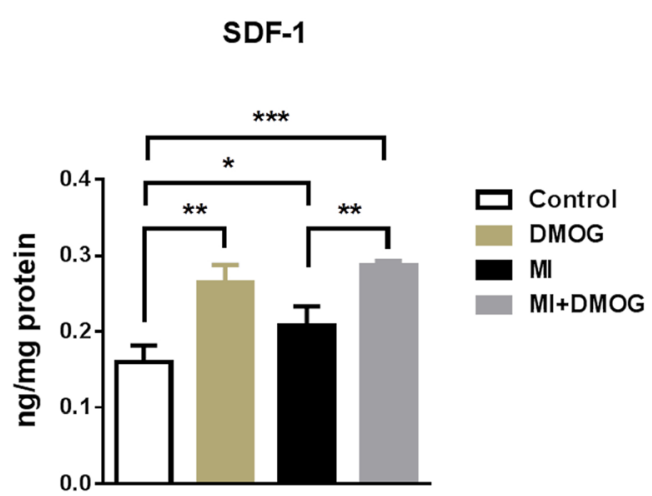

Fig. 3 Prolonged HIF- $1 \alpha$ and SDF-1 upregulation after DMOG treatment. a HIF- $1 \alpha$ expression in the cytosol and the nuclear fraction of non-infarcted (C), non-infarcted + DMOG (D), infarcted (MI), and infarcted + DMOG (MI + D)-treated mouse hearts determined by Western blot. DMOG was administered for 7 days. b Quantitative densitometric analysis of Western Blot replicates normalized to GAPDH (cytosol) and TBP (nuclear compartment). c Expression of HIF-1 $\alpha$ target genes VEGF-A, PDK1, and LDHA in non-infarcted and
E

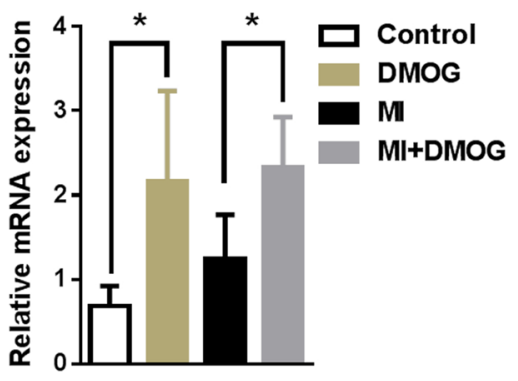

SDF-1 EGFP
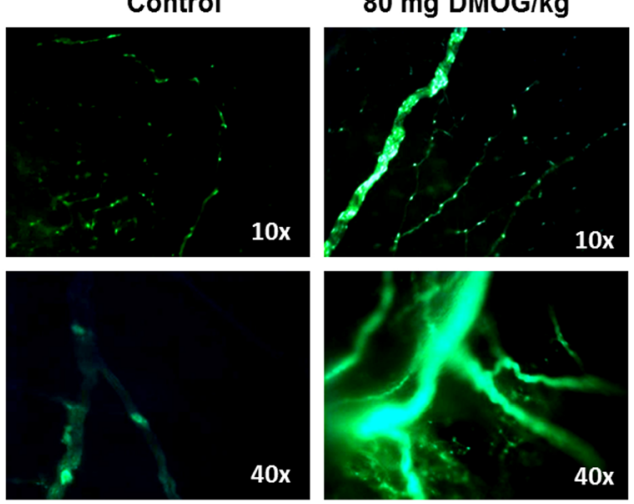

infarcted hearts \pm DMOG for 7 days. $\mathbf{d}$ ELISA for SDF-1 protein in heart lysates of non-infarcted and infarcted animals showed a significant upregulation of SDF-1protein in hearts of DMOG treated mice after 7 days of treatment. e SDF1-EGFP reporter mice treated with the prolyl-hydroxylase inhibitor DMOG $(80 \mathrm{mg} / \mathrm{kg}$, i.p.) showed a robust induction of SDF1-EGFP activity in coronary artery vessels and capillary networks in the heart. All data represent mean $\pm \mathrm{SD}(n=3)$; ${ }^{*} p<0.05 ; * * p<0.01 ; * * * p<0.001$

Lin-/c-kit+/Sca-1+, and Sca-1+ were significantly increased (Fig. 1c), whereas CD45-/CXCR4-EGFP+ cells did not significantly change after MI (Supp. Fig. 2B). Further immunostainings confirmed that CXCR4-EGFP+ cells were almost absent under normoxic conditions in the heart (Supp. Fig. 3, first row). Seven days after ischemia, CXCR4-EGFP+ could be co-stained in well as stem cell populations like $\mathrm{CD} 133+$, c-kit+, and 
A $\mathrm{CD}^{+} /$CXCR4-EGFP ${ }^{+}$cells in the heart

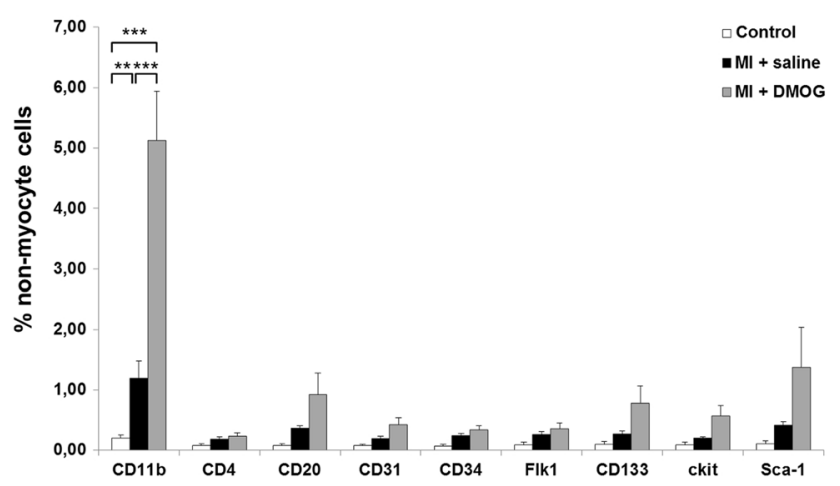

B

CXCR4-EGFP+/CD11b ${ }^{+}$cells in the heart

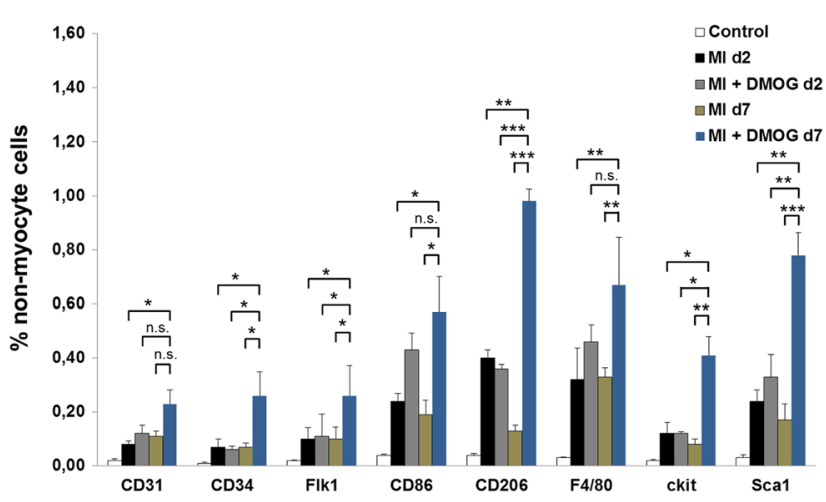

C

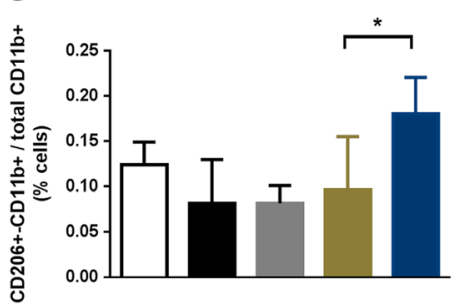

D

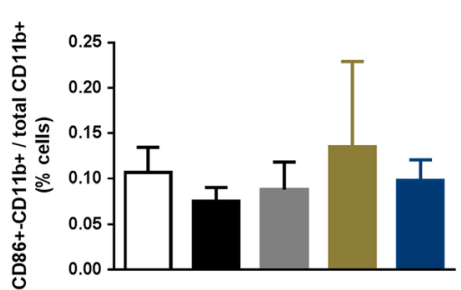

$\mathbf{E}$

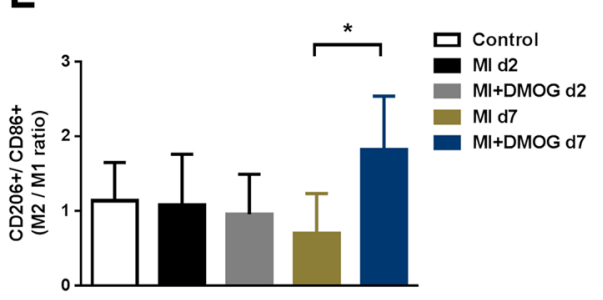

Fig. 4 DMOG increased CD45+/CXCR4-EGFP+ cells in the ischemic heart. a FACS analyses of CXCR4-EGFP reporter mice showed increased numbers of CD45+/CXCR4-EGFP+/CD11b+ cells in the ischemic heart after DMOG treatment. b Further analyses of CXCR4+/ $\mathrm{CD} 11 \mathrm{~b}+$ subpopulations revealed an increased expression of Sca1+, CD86+, CD206+, and F4/80+ cells particularly 7 days after PHI. c Bar graph representing the number of CXCR4-EGFP+ CD206+/CD11b+ to

PECAM (CD31)-positive endothelial cells and infiltrating CD11b+ monocytic cells (Supp. Fig. 3).

\section{DMOG upregulates SDF-1 and CXCR4 mRNA} expression in human endothelial and smooth muscle cells in vitro and murine $B M$ in vivo

Since SDF-1 and CXCR4 are known HIF-1 $\alpha$ target genes [10,11], we hypothesized that DMOG-induced PH inhibition upregulates SDF-1 and CXCR4 mRNA expression in endothelial, smooth muscle, and BM cells known to express either SDF-1 or CXCR4 [3, 17]. In vitro, cultivated human endothelial HMEC-1 and aortic vascular smooth muscle HAVSMC cells were treated with $500 \mu \mathrm{M}$ of DMOG known to induce HIF-1 target gene expression [18]. SDF-1 as well as CXCR4 mRNA expression was analyzed $1,2,4,6$, and $24 \mathrm{~h}$ after DMOG administration. SDF-1 mRNA expression was significantly elevated in human endothelial HMEC-1 cells $24 \mathrm{~h}$ after treatment (Fig. 2a). CXCR4 was upregulated earlier starting $4 \mathrm{~h}$ after DMOG treatment reaching a maximum after $24 \mathrm{~h}$ (Fig. 2b). Other known HIF-1 $\alpha$ target genes like VEGF-A, PDK1, and LDHA were also significantly upregulated after DMOG total CXCR4-EGFP+ CD11b+ cells. $\mathbf{d}$ Bar graph showing the number of CXCR4-EGFP+ CD86+/CD11b+ to total CXCR4-EGFP+ CD11b+ cells. e Bar graph showing the ratio of CXCR4-EGFP+ CD11b+/ CD206+ cells to CXCR4+-EGFP+ CD11b+/CD86+ cells in noninfarcted control and infarcted hearts \pm DMOG treatment for 2 and 7 days, respectively. Data represent mean $\pm \mathrm{SD}(n=6) ; * p<0.05 ; * * p<0.01$; $* * * p<0.001$

treatment in HMEC-1 cells (Supp. Fig. 4). In HAVSMC smooth muscle cells, SDF-1 mRNA was upregulated $24 \mathrm{~h}$ after DMOG treatment (Supp. Fig. 5A), whereas CXCR4 was almost undetectable (Supp. Fig. 5B).

In vivo, mice were treated with $80 \mathrm{mg} / \mathrm{kg}$ DMOG i.p. for 1 , 2 , and $6 \mathrm{~h}$ and analyzed for SDF-1 and CXCR4 mRNA expression in mononuclear BM cells. In contrast to SDF-1 mRNA, CXCR4 was significantly upregulated after $6 \mathrm{~h}$ of DMOG treatment (Fig. 2c, d).

\section{Upregulation of nuclear HIF- $1 \alpha$ and SDF-1 in the heart after $\mathbf{P H}$ inhibition in vivo}

Next, we determined whether DMOG is capable of inducing HIF- $1 \alpha$ and SDF-1 expression in the heart in vivo. HIF- $1 \alpha$ expression was determined in the cytosol and the nuclear fraction in non-infarcted and infarcted mouse hearts \pm DMOG administration by Western blot 7 days after MI. As shown in Fig. 3a, b, DMOG treatment significantly increased HIF- $1 \alpha$ expression in the nuclear but not in the cytosolic compartment in non-infarcted (D) and infarcted animals (MI + D), suggesting that HIF- $1 \alpha$ has translocated to the nucleus to 
A Control

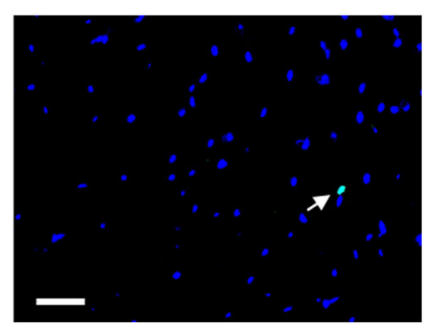

B

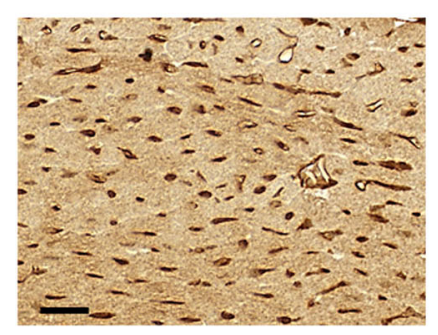

C

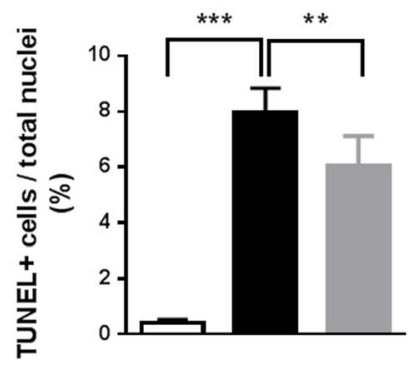

Fig. 5 DMOG treatment decreased apoptotic cells and increased neovascularization. a Representative co-staining of TUNEL-positive (bright green nuclei marked by arrows) and DAPI+ (blue nuclei) cells in non-infarcted and infarcted mice \pm DMOG treatment 30 days after MI. Scale bar represents $25 \mu \mathrm{M}$. b Representative immunohistochemical staining of CD31 (brown) in infarcted hearts 30 days after MI. Scale bar represents $25 \mu \mathrm{M}$. c Bar graph representing the percentage of

form its transcriptionally active compound. Other known HIF- $1 \alpha$ target genes like VEGF-A, PDK1, and LDHA were also significantly upregulated after 7 days of DMOG treatment in the mouse heart (Fig. 3c). Since SDF-1 is known to be downregulated from day 3 to day 7 after MI, we examined whether DMOG-induced $\mathrm{PH}$ inhibition leads to an upregulation of SDF-1 in the ischemic heart at later time points. As shown in Fig. 3d, DMOG treatment induced a significant upregulation of SDF-1 not only in non-infarcted but also in infarcted mouse hearts 7 days after MI. Furthermore, noninfarcted SDF-1-EGFP reporter mice were treated with $80 \mathrm{mg} / \mathrm{kg}$ of DMOG i.p. for $48 \mathrm{~h}(n=3$ animals per group). Thereafter, hearts were excised and investigated under a fluorescence microscope for SDF-1-EGFP reporter activity. Figure $3 \mathrm{e}$ reveals a pronounced activation of SDF1-EGFP in non-infarcted hearts after
MI
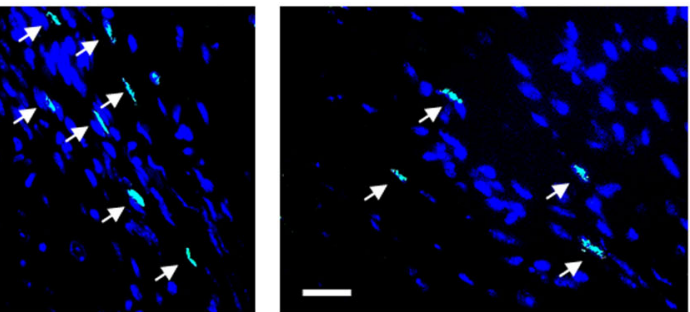

MI+DMOG
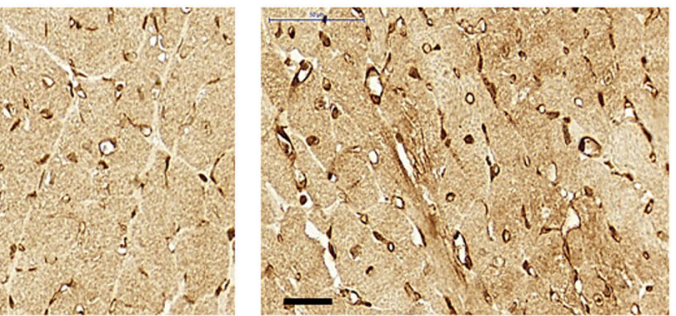

D

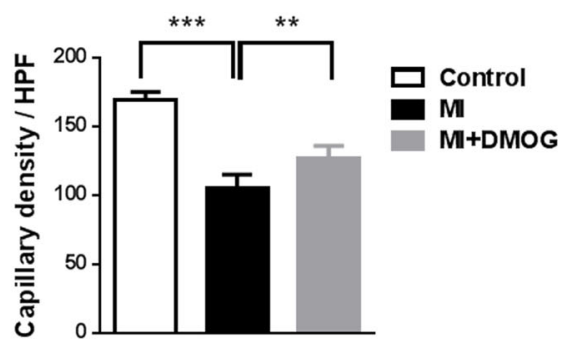

TUNEL-positive nuclei to total nuclei in the infarct border zone 30 days after MI. Data represent mean $\pm \mathrm{SD}(n=6)$. d Bar graph showing the numbers of $\mathrm{CD} 31+$ capillaries in the infarct border zone in non-infarcted control mice, infarcted mice, and infarcted mice treated with DMOG 30 days after MI. Data represent mean $\pm \mathrm{SD}(n=6)$; ** $p<0.01$, $* * * p<0.001$ (color figure online)

DMOG-induced PH inhibition compared to salinetreated controls.

\section{DMOG predominantly increased CD45+/CXCR4-EGFP+/CD11b+ cells after MI}

Since DMOG-induced PH inhibition prolonged SDF-1 upregulation in the infarcted heart for 7 days, we analyzed CXCR4EGFP+ cells in the ischemic heart. Therefore, non-infarcted and infarcted CXCR4-EGFP reporter mice were treated with saline or DMOG, respectively (Supp. Fig. 1). Seven days after $\mathrm{MI}$, hearts were excised and analyzed for CXCR4-EGFP+ and co-expression of the leukocyte common antigen CD45 by FACS. As shown in Fig. 4a, DMOG treatment revealed a significant upregulation of CD45+/CXCR4-EGFP+/CD11b+ monocytic cells after MI. CD45+/CXCR4-EGFP+ cells coexpressing T-lymphocytic CD4, B-lymphocytic CD20, 
A

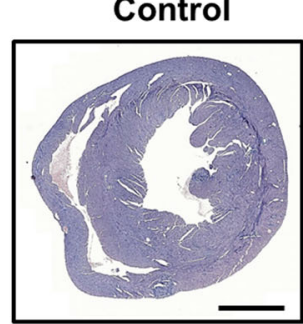

B

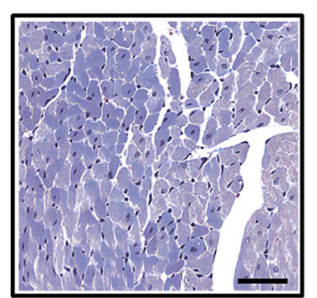

MI
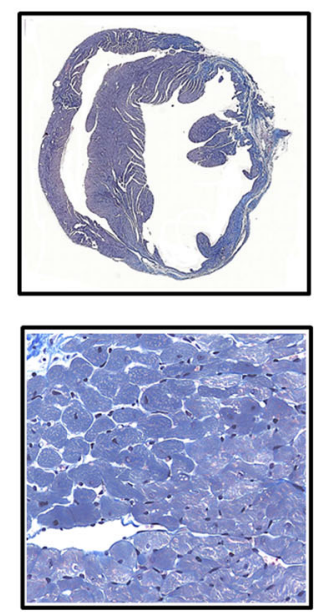

$\mathbf{E}$
MI+DMOG
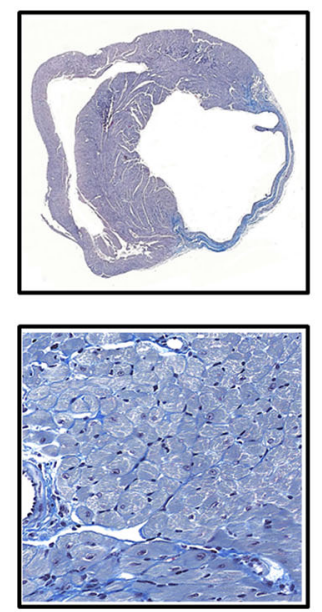

$\mathbf{F}$

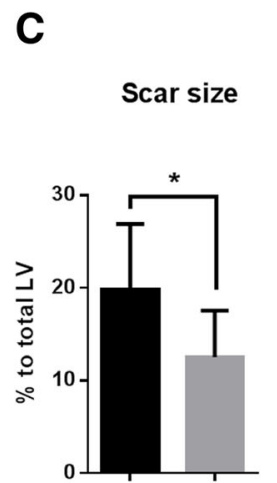

D

Myocyte diameter
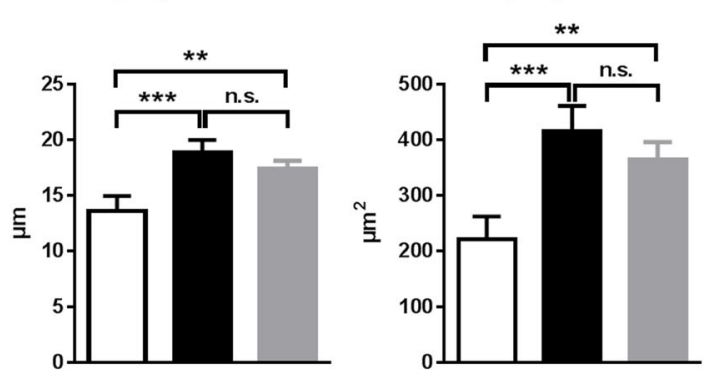

Ejection fraction (EF)

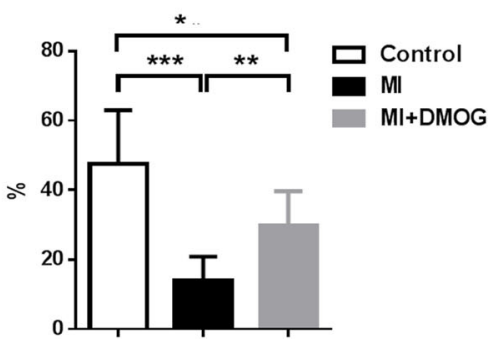

mice. $\mathbf{d}$ Bar graphs representing the minimum Feret's diameter and e cross-sectional area of cardiomyocytes in the infarct border zone of control, infarcted (MI), and infarcted + DMOG-treated (MI + DMOG) animals. $\mathbf{f}$ Diagram representing ejection fraction in sham $(n=5)$, saline + MI $(n=10)$, and DMOG + MI $(n=10)$ treated groups. All data represent mean $\pm \mathrm{SD} ; * p<0.05, * * p<0.01, * * * p<0.001$. n.s. not significant

Table 1 Mouse hemodynamic measurements

\begin{tabular}{lccc}
\hline Hemodynamic parameters & Control $(n=5)$ & MI $(n=10)$ & MI + DMOG $(n=10)$ \\
\hline HR $(\mathrm{bpm})$ & $343 \pm 82$ & $326 \pm 89$ & $347 \pm 91$ \\
Ves $(\mu \mathrm{L})$ & $16.46 \pm 7.12$ & $38.97 \pm 9.68$ & $22.73 \pm 10.91^{* *}$ \\
Ved $(\mu \mathrm{L})$ & $30.98 \pm 7.66$ & $44.82 \pm 8.55$ & $31.47 \pm 12.44^{*}$ \\
Pes $(\mathrm{mmHg})$ & $92.98 \pm 18.61$ & $86.26 \pm 11.15$ & $87.05 \pm 21.01$ \\
Ped $(\mathrm{mmHg})$ & $8.88 \pm 1.65$ & $11.72 \pm 7.00$ & $6.48 \pm 5.10$ \\
$\mathrm{SV}(\mu \mathrm{L})$ & $14.52 \pm 5.76$ & $5.85 \pm 1.64$ & $8.74 \pm 3.26^{*}$ \\
EF $(\%)$ & $47.46 \pm 15.56$ & $14.12 \pm 6.81$ & $29.69 \pm 9.95^{* *}$ \\
$\mathrm{CO}(\mu \mathrm{L} / \mathrm{min})$ & $5166 \pm 2547$ & $1963 \pm 953$ & $3046 \pm 1299^{*}$ \\
$\mathrm{SW}(\mathrm{mmHg} / \mu \mathrm{L})$ & $1251 \pm 314$ & $451 \pm 104$ & $806 \pm 335^{*}$ \\
Ea $(\mathrm{mmHg} / \mu \mathrm{L})$ & $6.39 \pm 2.83$ & $12.39 \pm 3.74$ & $9.34 \pm 2.58$ \\
Tau $(\mathrm{ms})$ & $12.07 \pm 3.71$ & $12.38 \pm 3.41$ & $9.22 \pm 2.52$ \\
\hline
\end{tabular}

Values are mean $\pm \mathrm{SD}$

$H R$ heart rate, Ves end-systolic volume, Ved end-diastolic volume, Pes end-systolic pressure, Ped end-diastolic pressure, $S V$ stroke volume, $E F$ ejection fraction, $C O$ cardiac output, $S W$ stroke work, $E a$ arterial elastance, Tau time constant for isovolumic relaxation.

$* p<0.05$ MI vs. MI + DMOG; ** $p<0.01 \mathrm{MI}$ vs. MI + DMOG 
angiogenic CD31, CD34, Flk-1, as well as stem cell markers like CD133, c-kit, and Sca-1 were not significantly increased after enhanced PH inhibition with DMOG. CD45-/CXCR4EGFP+ cells were very rarely detected and did not significantly change after MI \pm DMOG (Supp. Fig. 6).

\section{DMOG highly increased the ratio of CD11b+/CD206+ compared to $\mathrm{CD11b}+/ \mathrm{CD86}+$ cells in the ischemic heart}

Since CD11b+ cells are known to enhance angiogenesis [19] and play a major role in inflammatory and reparative processes after tissue injury, further potentially angiogenic subsets of $\mathrm{CD} 11 \mathrm{~b}+$ cells were analyzed at day 2 and day 7 after $\mathrm{MI} \pm \mathrm{DMOG}$ treatment, reflecting the early and late phase of inflammatory response after myocardial infarction with the major impact on cell infiltration [20,21]. Endothelial markers like CD31, CD34, Flk-1, macrophages markers for M1 type inflammatory CD86, M2-like reparative CD206 and F4/80 cells, as well as stem cell markers like c-kit and Sca-1 were used to further characterize CD11b+ cell subsets in vivo. As shown in Fig. 4b, increased PH inhibition with DMOG significantly upregulated CXCR4+/CD11b+ cells coexpressing angiogenic CD34, Flk-1, M1 like CD86, M2 like CD206, F4/80, and stem cell markers like c-kit and Sca-1 particularly at 7 days but not at 2 days after MI. Next, we calculated the ratio of reparative M2-like CXCR4-EGFP+ CD206+CD11b+ cells to total CXCR4-EGFP+CD11b+ cells (Fig. 4c) as well as the ratio of inflammatory M1-like CXCR4EGFP+ CD86+CD11b+ to total CXCR4-EGFP+ CD11b+ cells (Fig. 4d). As shown in Fig. 4c, DMOG treatment significantly increased the subset of CD206+ cells within the $\mathrm{CD} 11 \mathrm{~b}+$ cell population of CXCR4-EGFP+ cells. Moreover, DMOG treatment for 7 days after MI significantly increased the ratio of CXCR4-EGFP+ CD11b+/CD206+ cells to $\mathrm{CD} 11 \mathrm{~b}+/ \mathrm{CD} 86+$ cells by 2.6 -fold from 0.7 to 1.82 compared with infarcted control animals, suggesting an improved finetuning of reparative M2-like CD206+ compared to inflammatory CD86+ cells in the ischemic heart (Fig. 4e).

\section{Prolyl-hydroxylase inhibition reduced apoptotic cells and increased neovascularization}

Since PH-inhibitor treatment was administered for 7 days, we analyzed apoptotic cell death and neovascularization at a later time point 4 weeks after MI. Hearts were excised and histologically examined for apoptotic cells by TUNEL assay. Apoptotic index (AI) was calculated as percentage of apoptotic nuclei/total nuclei. AI in DMOG-treated mice was significantly reduced compared to saline-treated infarcted animals $(6.03 \pm 1.08$ vs. $8.00 \pm 0.86, p \leq 0.001$; Fig. 5a, c). Neovascularization was quantified by counting CD31+ vessels in the periinfarct region. As shown in Fig. 5b, d, numbers of
CD31+ vessels were significantly increased after treatment with DMOG compared to saline-treated infarcted animals $(127.1 \pm 3.6$ vs. $105 \pm 4.1, p \leq 0.002)$.

\section{DMOG treatment reduced scar size and improved myocardial function}

Since DMOG treatment reduced apoptotic cell death and increased neovascularization, we analyzed important determinants for cardiac remodeling like scar size, hypertrophic response, and heart function. Four weeks after MI, hearts were excised and histologically examined for infarct scar size and wall thickness. Scar size in DMOG-treated mice was significantly smaller compared to saline-treated infarcted animals $(12.5 \pm 2.5$ vs. $19.8 \pm 2.4 \%, p<0.05$; Fig. 6 a, b) although expression of the fibrosis marker collagen-1a was not significantly different 7 days after MI (Supp. Fig. 7A). The thickness of the infarcted and non-infarcted left ventricular wall was not significantly different between the two groups (infarct site $0.34 \pm 0.16$ vs. $0.32 \pm 0.07 \mathrm{~mm}, p=0.92$; periinfarct site $1.13 \pm 0.18$ vs. $1.10 \pm 0.08 \mathrm{~mm}, p=0.87$ ). Compared to control, infarcted mice \pm DMOG treatment revealed a significantly increased minimum Feret's diameter and crosssectional area of cardiomyocytes in the periinfarct region as signs of hypertrophic response after MI. Although there was a tendency to decreased values after DMOG administration, we found no significantly difference between infarcted animals \pm DMOG treatment (Fig. 6b, d, e). Furthermore, there was no difference in the expression of the hypertrophy marker brain natriuretic peptide (BNP) between DMOG and non-treated infarcted animals 7 days after MI (Supp. Fig. 7B).

To analyze hemodynamic effects of DMOG treatment, pressure volume relations were measured in vivo from sham-operated, saline-treated infarcted, or DMOG-treated infarcted mice, respectively (Table 1 and Fig. 6f). Compared to saline MI, DMOG treatment revealed a significantly improved systolic function, reflected by an increased ejection fraction $(29.69 \pm 9.95$ vs. $14.12 \pm 6.81 \%, p<0.01$; Fig. $6 f)$. Other important hemodynamic parameters like stroke volume, cardiac output, and stroke work were also significantly improved in DMOG-treated mice (Table 1). Furthermore, increased PH inhibition with DMOG revealed attenuated ventricular dilation, measured by end-diastolic volumes (Table 1).

\section{Discussion}

We show for the first time that systemic application of the prolyl-hydroxylase inhibitor DMOG after MI (1) upregulates nuclear HIF- $1 \alpha$ and SDF-1 in the ischemic mouse heart in vivo associated with increased (2) recruitment of mainly CD45+/CXCR4-EGFP+/CD11b+ cell subsets. DMOG treatment increased the ratio of CXCR4-EGFP+ CD11b+/ 


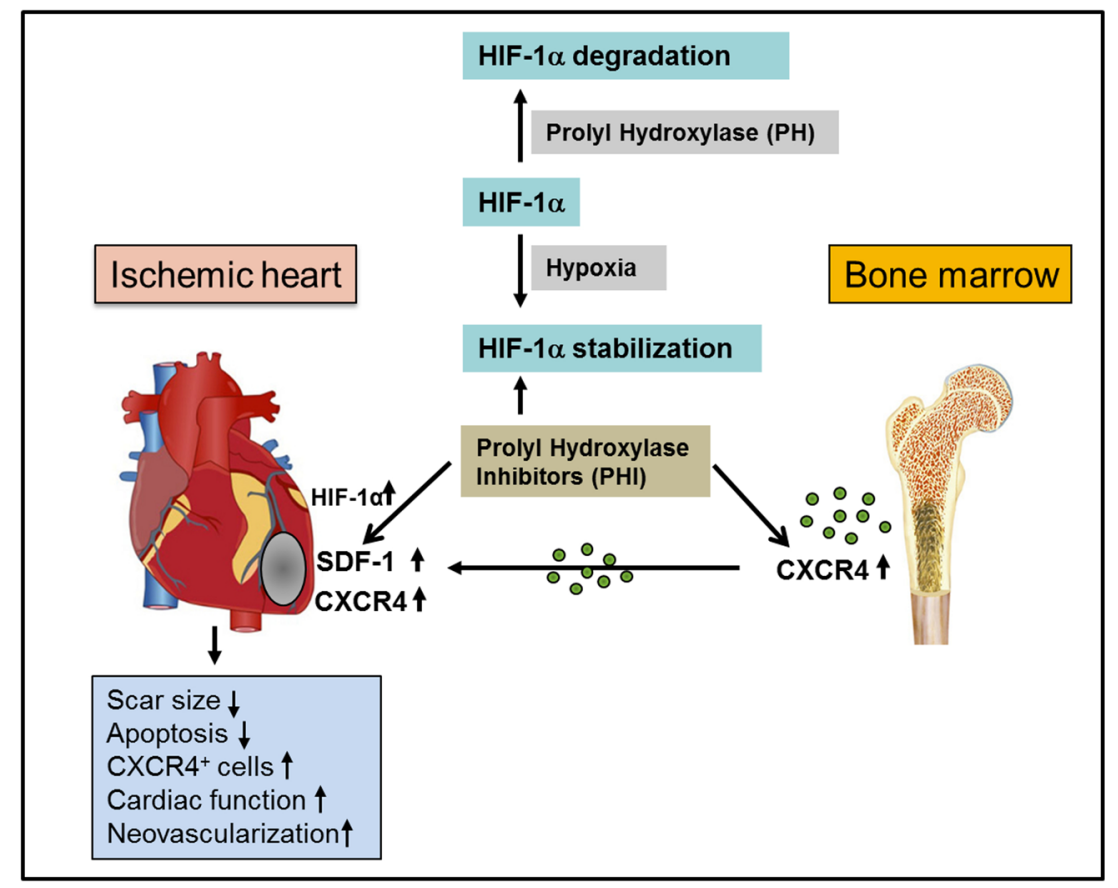

Fig. 7 Therapeutic concept of prolyl-hydroxylase inhibition to enhance SDF-1 and CXCR4 expression for myocardial repair. Under normoxic conditions, HIF- $1 \alpha$ protein is inactivated by prolyl-hydroxylases leading to HIF- $1 \alpha$ degradation. Hypoxia or PHI leads to a reduced prolylhydroxylases activity, thereby stabilizing HIF-1 $\alpha$, which translocates to the nucleus and upregulates downstream target genes like SDF-1 and CXCR4. HIF-1 $\alpha$ dependent SDF-1 upregulation lasts only for up to

CD206+ to CD11b+/CD86+ cells by 2.6-fold, suggesting an improved fine-tuning of reparative M2-like CD206+ compared to inflammatory CD86+ cells in the ischemic heart associated with (3) reduced apoptotic cell death, increased neovascularization, reduced scar size, and (4) an improved heart function after MI (Fig. 7). SDF-1 and CXCR4 gene expression during ischemia is regulated by HIF- $1 \alpha[10,11]$. Since SDF-1 is only upregulated for up to $72 \mathrm{~h}$ after MI [6], various groups have implemented strategies to overexpress SDF-1 mRNA or deliver SDF-1 protein [6-9]. However, these studies are based on invasive open chest protocols, whereas our study provides the clinical perspective that a non-invasive systemic application of a prolyl-hydroxylase inhibitor could upregulate SDF-1 and other HIF- $1 \alpha$ target genes to improve cardiac repair. Our results are in line with previous studies showing that preconditioning with DMOG can protect hearts from ischemic damage and improve cardiac function [22, 23]. A recently published study even showed that mice exposed to systemic hypoxemia for 2 weeks after MI revealed reactivation of cardiomyocyte mitosis [24]. Studies investigating the effect of prolyl-hydroxylase inhibition after the ischemic event also required open chest protocols with intracardiac injections of short hairpin RNAs or DMOG. One study showed that short hairpin RNA silencing of prolyl-hydroxylase enhances stem cell migration associated with improved angiogenesis
3 days after MI. In order to prolong and upregulate the expression of the HIF-1a target genes SDF-1 and CXCR4, pharmacological induced inhibition of prolyl-hydroxylases can be exploited to increase CXCR4+ cells in myocardial repair associated with reduced apoptotic cell death, increased neovascularization, reduced infarct size, and improved myocardial function

and heart function after MI $[25,26]$. However, effects on SDF-1/CXCR4-mediated cell recruitment were not investigated. Another recently published study suggests that early activation of CXCR4 in cardiomyocytes after intramyocardial injection of DMOG improved myocardial function by preventing cardiomyocyte cell death [12]. In line with these reports, we also found reduced numbers of apoptotic cells and increased neovascularization even at later time points after DMOG treatment. Of note, our study differs from Mayorga et al. in several important points: DMOG was injected after MI directly into the heart by a single injection, whereas we administered the drug systemically for up to 7 days after MI. Neither HIF- $1 \alpha$ upregulation nor expression of SDF- 1 or any other HIF-1 target gene except CXCR4 was analyzed. Although CXCR4 expression was upregulated in the heart, CXCR4+ cell populations in BM and heart after $\mathrm{MI} \pm$ DMOG treatment were not investigated. They also did not show a reduction in scar size after DMOG treatment. Thus, our data extends the current knowledge on the impact of increased $\mathrm{PH}$ inhibition on HIF- $1 \alpha$ triggered activation of the cellular SDF-1/CXCR4 axis. Up to date, it is not known which subpopulation of CXCR4+ cells predominantly orchestrates infarct healing. Our CXCR4-EGFP cell tracking model utilizing a broad panel of different leukocyte cell markers revealed that particularly the subpopulation of CD45+/ 
CXCR4+/CD11b+ cells was highly upregulated by ischemia \pm DMOG treatment, suggesting a prominent role in CXCR4/ SDF-1-mediated repair mechanisms. CD11b non-covalently associates with integrin $\beta 2$ (CD18) and is expressed on granulocytes, monocytes/macrophages, dendritic cells, NK cells, and subsets of T and B cells [27]. CD11b/CD18 is critical for the transendothelial migration of monocytes and neutrophils. It is also involved in granulocyte adhesion, phagocytosis, and neutrophil activation [27]. Indeed, CD11b has been linked to enhanced angiogenesis by the secretion of angiogenic growth factors and support of sprouting and proliferation of endogenous endothelial cells [19]. Moreover, a recently published study suggests that CD11b+ myeloid cells infiltrating the heart are capable of secreting leucine-rich a2-glycoprotein attenuating myocardial fibrosis and increasing angiogenesis [28]. Of note, the ratio of M2-like CXCR4-EGFP+CD11b+/ CD206+ cells to inflammatory M1-like CD11b+/CD86+ cells increased by 2.6-fold after DMOG-induced $\mathrm{PH}$ inhibition compared to infarcted control mice, suggesting an improved fine-tuning of reparative M2-like cells in the ischemic heart after 7 days. In line with that observation, CD206+ cells have been reported to support myocardial repair whereas the subpopulation of CD86+ cells reflects the early phase of inflammation which is involved in clearing of cell debris [29]. Depletion of CD206+ M2 macrophages by a CSF-1R kinase inhibitor was associated with decreased ventricular function, infarct enlargement, and increased inflammatory cell infiltration [30]. Recently published data even showed that depletion of CD11b+/CD206+ M2-like macrophages in mice lacking the kinase TRIB1 resulted in a catastrophic prognosis with frequent cardiac ruptures, as the result of markedly reduced collagen fibril formation in the infarct area due to impaired fibroblast activation. M2 like CD11b+/CD206+ cells also expressed higher levels of anti-inflammatory and repairassociated genes like interleukin 10 and VEGFA compared to M1 like macrophages. Decreased tissue repair and impaired cardiac function could be rescued by intrapericardial injection of $2 \times 105$ BM derived M2-like macrophages [31]. In our study, the $\mathrm{M} 2 / \mathrm{M} 1$ ratio increased by 2.6 -fold and numbers of CXCR4+/CD11b+/CD206+ cells were upregulated >7fold after DMOG treatment for 7 days after MI. Based on previous data, we estimate that the intact adult mouse heart contains around $7 \times 106$ non-myocytes $[32,33]$ which can rise ca. 10-fold due to cell infiltration and proliferation after MI $[20,34,35]$. A fraction of $1 \%$ CXCR4+/CD11b+/CD206+ cells in a total-heart non-myocyte suspension after $\mathrm{MI}$ and DMOG treatment would mean around $7 \times 10^{5}$ $\left(10 \times 7 \times 10^{6} \times 0.01\right) \mathrm{CXCR} 4+/ \mathrm{CD} 11 \mathrm{~b}+/ \mathrm{CD} 206+$ cells exceeding the numbers of injected reparative M2-like macrophages $\left(2 \times 10^{5}\right)$ by far. Thus, increasing numbers of CXCR4+/CD11b+/CD206+ cells after MI with DMOG treatment could have a major biologically impact in the heart. Since increased PH inhibition with DMOG induced SDF-1 upregulation for 7 days after MI, the shift in favor of CD206 M2 like cells might be explained by an enhanced migration capacity towards SDF-1 compared to M1 like macrophages as described previously [36]. Furthermore, SDF-1/CXCR4 interactions might promote M2 polarization $[37,38]$. Since CD11b is also a surface marker for neutrophils the latter may have facilitated post-infarction healing by polarizing macrophages towards a reparative M2c phenotype [39]. Improvement of heart function in our study could be explained by several reasons: scar size and end-diastolic volumes were reduced reflecting attenuated infarct remodeling; second perfusion and contractile tissue might be preserved due to increased capillary density and reduced apoptotic cell death in the periinfarct region. This effect might be related to SDF-1mediated activation of the survival factor protein kinase $\mathrm{B}$ (PKB/Akt) known to increase neovascularization and reduce cardiomyocyte apoptosis [40]. Third, we found an increased M2/M1 ratio associated with improved cardiac function and survival as mentioned previously [31]. Moreover, CXCR4EGFP+/CD11b+ cells co-expressing angiogenic markers like CD34, Flk1, or stem cell markers like c-kit and Sca-1 might have also contributed to improved neovascularization [41].

\section{Limitations of the study}

One of the major limitations of our study is that we cannot rule out the possibility that DMOG activation of other HIF-1 target genes such as VEGF or EPO might have contributed to the observed benefits [23]. Also, DMOG-related mechanisms which have been described in terms of preconditioning like induction of protective endoplasmic reticulum stress genes [42] or prevention of activation of the ATR/CHK1/p53 pathway to decrease apoptosis might also play a role in cardioprotection [43]. With respect to the study design, we could have conducted apoptosis assays at an earlier time point and could have complemented functional assessment by echo data. The detailed mechanism why the ratio of $\mathrm{M} 2 / \mathrm{M} 1$ shifted after $\mathrm{PH}$ inhibition and the role of other $\mathrm{CXCR} 4+/ \mathrm{CD} 11 \mathrm{~b}+$ cell populations remains to be resolved in future studies. Nevertheless, our study assumes an additional mechanism of PH inhibitor induced upregulation of nuclear HIF-1 $\alpha$ and SDF-1 to stimulate CXCR4+/CD11b+ cell recruitment for cardiac repair. Since DMOG may not have the proper pharmacological profile for use in humans [44], other prolylhydroxylase inhibitors like FG-4592, which has recently been shown to corrected anemia in hemodialysis patients, may be applicable to clinical practice [45].

Our data suggest increased $\mathrm{PH}$ inhibition as a promising tool for a customized upregulation of SDF-1 and CXCR4 expression to attract reparative CXCR4+/CD11b+ cells to the ischemic heart associated with increased cardiac repair. 
Acknowledgments Open access funding provided by Austrian Science Fund (FWF). This work was supported by the German Research Foundation (DFG ZA 575/4-1), the German Heart Research Foundation (DSHF F/27/11) and the Austrian Science Fund (FWF P 28817-B28).

Compliance with ethical standards Animal care and all experimental procedures are performed in strict accordance to the Austrian and National Institutes of Health animal legislation guidelines.

Conflict of interest The authors declare no conflict of interest related to the study.

Open Access This article is distributed under the terms of the Creative Commons Attribution 4.0 International License (http:// creativecommons.org/licenses/by/4.0/), which permits unrestricted use, distribution, and reproduction in any medium, provided you give appropriate credit to the original author(s) and the source, provide a link to the Creative Commons license, and indicate if changes were made.

\section{References}

1. McMurray JJ, Adamopoulos S, Anker SD, Auricchio A, Bohm M, Dickstein K, Falk V, Filippatos G, Fonseca C, Gomez-Sanchez MA et al (2012) ESC Guidelines for the diagnosis and treatment of acute and chronic heart failure 2012: the Task Force for the Diagnosis and Treatment of Acute and Chronic Heart Failure 2012 of the European Society of Cardiology. Developed in collaboration with the Heart Failure Association (HFA) of the ESC. Eur Heart J 33: $1787-1847$

2. Steg PG, James SK, Atar D, Badano LP, Blomstrom-Lundqvist C, Borger MA, Di Mario C, Dickstein K, Ducrocq G, FernandezAviles F et al (2012) ESC Guidelines for the management of acute myocardial infarction in patients presenting with ST-segment elevation. Eur Heart J 33:2569-2619

3. Zaruba MM, Franz WM (2010) Role of the SDF-1-CXCR4 axis in stem cell-based therapies for ischemic cardiomyopathy. Expert Opin Biol Ther 10:321-335

4. Zaruba MM, Theiss HD, Vallaster M, Mehl U, Brunner S, David R, Fischer R, Krieg L, Hirsch E, Huber B et al (2009) Synergy between CD26/DPP-IV inhibition and G-CSF improves cardiac function after acute myocardial infarction. Cell Stem Cell 4:313-323

5. Zaruba MM, Zhu W, Soonpaa MH, Reuter S, Franz WM, Field LJ (2012) Granulocyte colony-stimulating factor treatment plus dipeptidylpeptidase-IV inhibition augments myocardial regeneration in mice expressing cyclin D2 in adult cardiomyocytes. Eur Heart J 33:129-137

6. Abbott JD, Huang Y, Liu D, Hickey R, Krause DS, Giordano FJ (2004) Stromal cell-derived factor-1 \{alpha\} plays a critical role in stem cell recruitment to the heart after myocardial infarction but is not sufficient to induce homing in the absence of injury. Circulation 8:8

7. Askari AT, Unzek S, Popovic ZB, Goldman CK, Forudi F, Kiedrowski M, Rovner A, Ellis SG, Thomas JD, DiCorleto PE et al (2003) Effect of stromal-cell-derived factor 1 on stem-cell homing and tissue regeneration in ischaemic cardiomyopathy. Lancet 362:697-703

8. Zhang G, Nakamura Y, Wang X, Hu Q, Suggs LJ, Zhang J (2007) Controlled release of stromal cell-derived factor- 1 alpha in situ increases c-kit+ cell homing to the infarcted heart. Tissue Eng 13: 2063-2071

9. Segers VFM, Tokunou T, Higgins LJ, MacGillivray C, Gannon J, Lee RT (2007) Local delivery of protease-resistant stromal cell derived factor-1 for stem cell recruitment after myocardial infarction. Circulation 116:1683-1692

10. Ceradini DJ, Kulkarni AR, Callaghan MJ, Tepper OM, Bastidas N, Kleinman ME, Capla JM, Galiano RD, Levine JP, Gurtner GC (2004) Progenitor cell trafficking is regulated by hypoxic gradients through HIF-1 induction of SDF-1. Nat Med 10:858-864

11. Schioppa T, Uranchimeg B, Saccani A, Biswas SK, Doni A, Rapisarda A, Bernasconi S, Saccani S, Nebuloni M, Vago L et al (2003) Regulation of the chemokine receptor CXCR4 by hypoxia. J Exp Med 198:1391-1402

12. Mayorga M, Kiedrowski M, Shamhart P, Forudi F, Weber K, Chilian WM, Penn MS, Dong F (2015) Early up-regulation of myocardial CXCR4 expression is critical for dimethyloxalylglycine (DMOG) induced cardiac improvement in acute myocardial infarction (MI). Am J Physiol Heart Circ Physiol: ajpheart.00449.02015. doi: 10.1152/ajpheart.00449.2015

13. Dimauro I, Pearson T, Caporossi D, Jackson MJ (2012) A simple protocol for the subcellular fractionation of skeletal muscle cells and tissue. BMC research notes 5:513

14. Pfeffer JM, Pfeffer MA, Fletcher PJ, Braunwald E (1991) Progressive ventricular remodeling in rat with myocardial infarction. Am J Phys 260:H1406-H1414

15. Deindl E, Zaruba MM, Brunner S, Huber B, Mehl U, Assmann G, Hoefer IE, Mueller-Hoecker J, Franz WM (2006) G-CSF administration after myocardial infarction in mice attenuates late ischemic cardiomyopathy by enhanced arteriogenesis. FASEB J 20:956-958

16. Bhattacharyya BJ, Banisadr G, Jung H, Ren D, Cronshaw DG, Zou Y, Miller RJ (2008) The chemokine stromal cell-derived factor-1 regulates GABAergic inputs to neural progenitors in the postnatal dentate gyrus. J Neurosci 28:6720-6730

17. Abi-Younes S, Sauty A, Mach F, Sukhova GK, Libby P, Luster AD (2000) The stromal cell-derived factor- 1 chemokine is a potent platelet agonist highly expressed in atherosclerotic plaques. Circ Res 86:131-138

18. Ockaili R, Natarajan R, Salloum F, Fisher BJ, Jones D, Fowler AA 3rd, Kukreja RC (2005) HIF-1 activation attenuates postischemic myocardial injury: role for heme oxygenase- 1 in modulating microvascular chemokine generation. Am J Physiol Heart Circ Physiol 289:H542-H548

19. Grunewald M, Avraham I, Dor Y, Bachar-Lustig E, Itin A, Jung S, Chimenti S, Landsman L, Abramovitch R, Keshet E (2006) VEGFinduced adult neovascularization: recruitment, retention, and role of accessory cells. Cell 124:175-189

20. Liehn EA, Tuchscheerer N, Kanzler I, Drechsler M, Fraemohs L, Schuh A, Koenen RR, Zander S, Soehnlein O, Hristov M et al (2011) Double-edged role of the CXCL12/CXCR4 axis in experimental myocardial infarction. J Am Coll Cardiol 58:2415-2423

21. van Amerongen MJ, Harmsen MC, van Rooijen N, Petersen $\mathrm{AH}$, van Luyn MJ (2007) Macrophage depletion impairs wound healing and increases left ventricular remodeling after myocardial injury in mice. Am J Pathol 170:818-829

22. Eckle T, Kohler D, Lehmann R, El Kasmi K, Eltzschig HK (2008) Hypoxia-inducible factor-1 is central to cardioprotection: a new paradigm for ischemic preconditioning. Circulation 118:166-175

23. Poynter JA, Manukyan MC, Wang Y, Brewster BD, Herrmann JL, Weil BR, Abarbanell AM, Meldrum DR (2011) Systemic pretreatment with dimethyloxalylglycine increases myocardial HIF-1alpha and VEGF production and improves functional recovery after acute ischemia/reperfusion. Surgery 150:278-283

24. Nakada Y, Canseco DC, Thet S, Abdisalaam S, Asaithamby A, Santos CX, Shah AM, Zhang H, Faber JE, Kinter MT et al (2017) Hypoxia induces heart regeneration in adult mice. Nature 541:222-227

25. Huang M, Nguyen P, Jia F, Hu S, Gong Y, de Almeida PE, Wang L, Nag D, Kay MA, Giaccia AJ et al (2011) Double knockdown of 
prolyl hydroxylase and factor-inhibiting hypoxia-inducible factor with nonviral minicircle gene therapy enhances stem cell mobilization and angiogenesis after myocardial infarction. Circulation 124: S46-S54

26. Paik KJ, Maan ZN, Zielins ER, Duscher D, Whittam AJ, Morrison SD, Brett EA, Ransom RC, Hu MS, Wu JC et al (2016) Short hairpin RNA silencing of PHD-2 improves neovascularization and functional outcomes in diabetic wounds and ischemic limbs. PLoS One 11:e0150927

27. Solovjov DA, Pluskota E, Plow EF (2005) Distinct roles for the alpha and beta subunits in the functions of integrin alphaMbeta2. J Biol Chem 280:1336-1345

28. Kumagai S, Nakayama H, Fujimoto M, Honda H, Serada S, Ishibashi-Ueda H, Kasai A, Obana M, Sakata Y, Sawa Y et al (2016) Myeloid cell-derived LRG attenuates adverse cardiac remodelling after myocardial infarction. Cardiovasc Res 109:272-282

29. Ben-Mordechai T, Holbova R, Landa-Rouben N, Harel-Adar T, Feinberg MS, Abd Elrahman I, Blum G, Epstein FH, Silman Z, Cohen S et al (2013) Macrophage subpopulations are essential for infarct repair with and without stem cell therapy. J Am Coll Cardiol 62:1890-1901

30. Leblond AL, Klinkert K, Martin K, Turner EC, Kumar AH, Browne T, Caplice NM (2015) Systemic and cardiac depletion of M2 macrophage through CSF-1R signaling inhibition alters cardiac function post myocardial infarction. PLoS One 10:e0137515

31. Shiraishi M, Shintani Y, Shintani Y, Ishida H, Saba R, Yamaguchi A, Adachi H, Yashiro K, Suzuki K (2016) Alternatively activated macrophages determine repair of the infarcted adult murine heart. $\mathrm{J}$ Clin Invest 126:2151-2166

32. Soonpaa MH, Field LJ (1997) Assessment of cardiomyocyte DNA synthesis in normal and injured adult mouse hearts. Am J Phys 272: $\mathrm{H} 220-\mathrm{H} 226$

33. Limana F, Urbanek K, Chimenti S, Quaini F, Leri A, Kajstura J, Nadal-Ginard B, Izumo S, Anversa P (2002) bcl-2 overexpression promotes myocyte proliferation. Proc Natl Acad Sci U S A 99: $6257-6262$

34. Yang F, Liu YH, Yang XP, Xu J, Kapke A, Carretero OA (2002) Myocardial infarction and cardiac remodelling in mice. Exp Physiol 87:547-555

35. Lutgens E, Daemen MJ, de Muinck ED, Debets J, Leenders P, Smits JF (1999) Chronic myocardial infarction in the mouse: cardiac structural and functional changes. Cardiovasc Res 41:586-593
36. Vogel DY, Heijnen PD, Breur M, de Vries HE, Tool AT, Amor S, Dijkstra CD (2014) Macrophages migrate in an activationdependent manner to chemokines involved in neuroinflammation. J Neuroinflammation 11:23

37. Beider K, Bitner H, Leiba M, Gutwein O, Koren-Michowitz M, Ostrovsky O, Abraham M, Wald H, Galun E, Peled A et al (2014) Multiple myeloma cells recruit tumor-supportive macrophages through the CXCR4/CXCL12 axis and promote their polarization toward the M2 phenotype. Oncotarget 5:11283-11296

38. Chatterjee M, von Ungern-Sternberg SN, Seizer P, Schlegel F, Buttcher M, Sindhu NA, Muller S, Mack A, Gawaz M (2015) Platelet-derived CXCL12 regulates monocyte function, survival, differentiation into macrophages and foam cells through differential involvement of CXCR4-CXCR7. Cell Death Dis 6:e1989

39. Horckmans M, Ring L, Duchene J, Santovito D, Schloss MJ, Drechsler M, Weber C, Soehnlein O, Steffens S (2016) Neutrophils orchestrate post-myocardial infarction healing by polarizing macrophages towards a reparative phenotype. Eur Heart J. doi:10.1093/eurheartj/ehw002

40. Sexana A, Fish JE, White MD, Yu S, Smyth JWP, Shaw RM, DiMaio JM, Srivastava D (2008) Stromal cell-derived factor-1alpha is cardioprotective after myocardial infarction. Circulation 117: 2224-2231

41. Madlambayan GJ, Butler JM, Hosaka K, Jorgensen M, Fu D, Guthrie SM, Shenoy AK, Brank A, Russell KJ, Otero J et al (2009) Bone marrow stem and progenitor cell contribution to neovasculogenesis is dependent on model system with SDF-1 as a permissive trigger. Blood 114:4310-4319

42. Natarajan R, Salloum FN, Fisher BJ, Smithson L, Almenara J, Fowler AA 3rd (2009) Prolyl hydroxylase inhibition attenuates post-ischemic cardiac injury via induction of endoplasmic reticulum stress genes. Vasc Pharmacol 51:110-118

43. Xie L, Pi X, Mishra A, Fong G, Peng J, Patterson C (2012) PHD3dependent hydroxylation of HCLK2 promotes the DNA damage response. J Clin Invest 122:2827-2836

44. Vachal P, Miao S, Pierce JM, Guiadeen D, Colandrea VJ, Wyvratt MJ, Salowe SP, Sonatore LM, Milligan JA, Hajdu R et al (2012) 1, 3,8-Triazaspiro[4.5]decane-2,4-diones as efficacious pan-inhibitors of hypoxia-inducible factor prolyl hydroxylase 1-3 (HIF PHD1-3) for the treatment of anemia. J Med Chem 55:2945-2959

45. Besarab A, Chernyavskaya E, Motylev I, Shutov E, Kumbar LM, Gurevich K, Chan DT, Leong R, Poole L, Zhong M et al (2015) Roxadustat (FG-4592): correction of anemia in incident dialysis patients. J Am Soc Nephrol. doi:10.1681/asn.2015030241 